\title{
lodine uptake and distribution in horticultural and fruit tree species
}

\author{
Alessandra Caffagni, ${ }^{1}$ Nicola Pecchioni, ${ }^{1}$ Pierluigi Meriggi, ${ }^{2}$ Valerio Bucci, ${ }^{3}$ Emidio Sabatini, ${ }^{4}$ \\ Nazareno Acciarri, ${ }^{4}$ Tommaso Ciriaci, ${ }^{4}$ Laura Pulcini, ${ }^{4}$ Nazzareno Felicioni, ${ }^{4}$ \\ Massimiliano Beretta, ${ }^{5}$ Justyna Milc ${ }^{1}$ \\ ${ }^{1}$ Department of Agricultural and Food Sciences, University of Modena and Reggio Emilia, Reggio \\ Emilia; ${ }^{2}$ Horta S.r.I., Spin Off Company Catholic University, Piacenza; ${ }^{3}$ Terremerse Soc. Coop., \\ Bagnacavallo, Ravenna; ${ }^{4}$ C.R.A.-ORA Agricultural Research Council, Research Unit 13 for Vegetable \\ Crops, Monsampolo del Tronto, Ascoli Piceno; ${ }^{5}$ C.R.A.-ORL Agricultural Research Council, Research \\ Unit 12 for Vegetable Crops, Montanaso Lombardo, Lodi, Italy
}

\begin{abstract}
Iodine is an essential microelement for humans and iodine deficiency disorder (IDD) is one of the most widespread nutrient-deficiency diseases in the world. Iodine biofortification of plants provides an attractive opportunity to increase iodine intake in humans and to prevent and control IDD. This study was conducted to investigate the iodine uptake and accumulation in the edible portion of two fruit trees (plum and nectarine) and two horticultural crops (tomato and potato). We tested two types of iodine treatment (soil and foliar spray application) and, for fresh market tomato, two production systems (open field and greenhouse hydroponic culture). We investigated the distribution of iodine in potato stem and leaves, and in plum tree fruit, leaves and branches. Iodine content of potato tubers after postharvest storage and processing (cooking), and of nectarine fruit after postharvest storage and processing (peeling) were also determined. Differences in iodine accumulation were observed among the four crops, between applications, and between production systems. In the open field, the maximum iodine content ranged from 9.5 and $14.3 \mu \mathrm{g} 100 \mathrm{~g}^{-1}$ for plum and
\end{abstract}

Correspondence: Dr. Nicola Pecchioni, Department of Agricultural and Food Sciences, University of Modena and Reggio Emilia, via G. Amendola, 2 Padiglione Besta - 42100 Reggio Emilia, Italy.

Tel. +39.0522.522003 - Fax: +39.0522 .522027 .

E-mail: nicola.pecchioni@unimore.it

Key words: biofortification, iodine, tomato, potato, plum; nectarine.

Acknowledgements: this research was supported by the IODOPLANT project, funded by the Italian Ministry of Agriculture Food and Forestry Policies.

Received for publication: 10 November 2011.

Accepted for publication: 18 February 2012.

(C) Copyright A. Caffagni et al., 2012

Licensee PAGEPress, Italy

Italian Journal of Agronomy 2012; 7:e32

doi:10.4081/ija.2012.e32

This article is distributed under the terms of the Creative Commons Attribution Noncommercial License (by-nc 3.0) which permits any noncommercial use, distribution, and reproduction in any medium, provided the original author(s) and source are credited. nectarine fruit, to 89.4 and $144.0 \mu \mathrm{g} 100 \mathrm{~g}^{-1}$ for potato tuber and tomato fruit, respectively. These results showed that nectarine and plum trees accumulated significantly smaller amounts of iodine in their edible tissues compared with potato and tomato. Results also showed hydroponic culture to be the most efficient system for iodine uptake in tomato, since its fresh fruit accumulated up to $2423 \mu \mathrm{g} 100 \mathrm{~g}^{-1}$ of iodine. In all species investigated, iodine was mainly stored in the leaves. Only a small portion of iodine was transported to plum tree branches and fruit, and to potato stems and tubers. No differences in iodine content were observed after peeling. A significant increase in iodine content of potato was observed after baking, whereas a significant decrease was observed after boiling. We concluded that iodine biofortified fresh market tomato salad, both from field and hydroponic cultivation, and baked potatoes can be considered potential functional foods for IDD prevention.

\section{Introduction}

Iodine is an essential microelement for mammals (Welch and Graham, 1999) with a unique role in organisms. In fact, it is an indispensable component of the thyroid hormones, thyroxine (T4) and triiodothyronine (T3), which are involved in the regulation of various enzymes and metabolic processes.

Inadequate dietary iodine intake can cause insufficient thyroxin production. This results in iodine deficiency disorder (IDD). The clinical manifestations of IDD include hypothyroidism, goiter, mental retardation, reproductive impairment, deaf-mutism, and lower child survival rates (Hetzel, 1983; Stanbury et al., 1998; Delange et al., 1999). The recommended daily nutrient intake of iodine is $50 \mu \mathrm{g}$ for infants (aged 0-12 months), $90 \mu \mathrm{g}$ for children (aged 2-6 years), 120 $\mu \mathrm{g}$ for schoolchildren (aged 7-12 years), $150 \mu \mathrm{g}$ for adolescents (aged over 12 years) and adults, and $200 \mu \mathrm{g}$ for pregnant and lactating women (WHO/UNICEF/ICCIDD, 1996). These amounts are thought to allow normal hormone production without stressing the thyroid iodide trapping mechanism. Excess iodine intake is more difficult to define. Many people habitually ingest huge amounts of iodine (approx. 10-200 $\mathrm{mg} \mathrm{day^{-1 }}$ ) with no evidence of negative effects (FAO/WHO, 2004).

In the human diet, seaweed, fish and shellfish, all of which absorb iodine from the water, are the best sources of iodine with amounts ranging from 163 to $3180 \mu \mathrm{g} \mathrm{kg}^{-1}$ fresh weight (FW). The iodine content of terrestrial foods is generally much lower, and concentrations vary widely according to geographical location: from 10 to a maximum $200 \mu \mathrm{g} \mathrm{kg}^{-1} \mathrm{FW}$ (FAO/WHO, 2004). 
In 1993, the WHO and UNICEF recommended universal salt iodization (USI) and iodine supplementation as highly effective strategies for preventing and controlling IDD (UNICEF/WHO, 1994) and USI programs are now applied in most countries. Despite this, approximately $31 \%$ (1,900.9 million) of the world population has insufficient iodine intake. The most affected regions are Europe and South-East Asia (WHO/UNICEF/ICCIDD, 2007). In 2005, Italy introduced legislation requiring retailers to sell only iodized salt; $30 \mathrm{ppm}$ as either potassium iodide (KI) or potassium iodate $\left(\mathrm{KIO}_{3}\right)$ unless consumers specifically request otherwise (Moleti et al., 2008). Nevertheless, in Italy there is still a low dietary supply with mild to moderate iodine deficiency (Andersson et al., 2007). Since the effectiveness of USI largely depends on the economic, social, and cultural context of the population in question, an alternative approach of biofortification could also be considered. Biofortification can be defined as the supplementation of trace elements in the food chain through plant uptake, and it is believed to be a cost effective strategy to reduce mineral malnutrition. Fortified food can be defined as functional foods, i.e. foods that provide a health benefit beyond basic nutritional functions (Henry, 2010).

Iodine is a non-essential element for higher plants, although all plants can assimilate it from soil. The capacity of the soil to absorb iodine is crucial for iodine fertilization. In humus and clay soils, iodine is fixed by organic matter and aluminium and iron oxides. Therefore, the plants grown in these soils have a low iodine content (Jopke et al., 1996). Iodine fertilization of these types of soils is less efficient in terms of iodine uptake when compared to sandy soils and water culture (Jopke et al., 1996; Zhu et al., 2003; Blasco et al., 2008; Voogt et al., 2010). In recent years, iodine biofortification has drawn the attention of researchers who have studied the capacity of edible crops to accumulate iodine. It has been demonstrated that iodine cannot be easily stored in the grains of cereals. In fact, Mackowiak and Grossl (1999) showed that even with high concentrations of iodide or iodate in growing solutions the iodine concentration in rice grains was still not sufficient to meet the recommended dietary allowance (RDA). Horticultural crops can store iodine, and its uptake increases with the quantity of iodine used, as demonstrated for potato (Caffagni et al., 2011), Chinese cabbage (Weng et al., 2003; Hong et al., 2008), radish (Weng et al., 2003), tomato (Hong et al., 2008; Caffagni et al., 2011; Landini et al., 2011), carrot (Dai et al., 2004; Hong et al., 2008), lettuce (Blasco et al., 2008; Hong et al., 2008; Voogt et al., 2010) and spinach (Weng et al., 2003; Zhu et al., 2003; Dai et al., 2004). Furthermore, different crops were shown to respond differently to increasing iodine dose in soil (Weng et al., 2003; Dai et al., 2004; Hong et al., 2008). However, at higher concentrations, iodine can be toxic, leading to leaf damage (chlorosis and necrosis) and stunted growth (Mackowiak and Grossl, 1999; Weng et al., 2008; Caffagni et al., 2011).

Iodine is stored better in the vegetative organs, such as root, stem and leaves (Dai et al., 2004; Voogt et al., 2010), suggesting differences in iodine accumulation among organs (Weng et al., 2003; Hong et al., 2008). Iodine biofortification studies, conducted in greenhouse conditions, showed an adequate iodine accumulation in crops such as spinach (Zhu et al., 2003; Dai et al., 2004), lettuce (Blasco et al., 2008; Voogt et al., 2010), tomato (Hong et al., 2008; Caffagni et al., 2011; Landini et al., 2011) or potato (Caffagni et al., 2011), making them favorite crops for iodine biofortification programs. Iodine content may also be influenced by other factors such as postharvest processing (e.g. peeling and cooking) and storage. These can largely determine final quality, whether a crop is sold for fresh consumption, or used as an ingredient in a processed food product (Winger et al., 2008).

This paper reports results obtained within the frame of the Italian national project IODOPLANT, aimed at iodine fortification of horticultural and fruit tree species. In particular, it was our aim to find suitable methods of iodine fortification to be applied in normal cultivation practice in Italy. The second aim was to study the effect of different posthar- vest treatments (peeling, storage and cooking) in one horticultural and one fruit tree species. The third aim was to study the distribution of the applied iodine in various organs of one horticultural and one fruit tree species.

\section{Materials and methods}

\section{Plant material and treatments}

Four cultivated plant species were used, two fruit trees (plum, Prunus domestica L. cv. Angeleno; nectarine, Prunus persica L. Batsch, cv. Big Top) and two horticultural crops (potato, Solanum tuberosum L. cv. Daisy; fresh market tomato, Solanum lycopersicum L. CRA breeding line Sel. 25/08, a small-fruited breeding line, of Datterino typology).

A field experiment was carried out from 2007 to 2009 on 8-year old plum trees [Prunus domestica L. cv. Angeleno grafted onto GF 677 rootstock (Prunus persica $\mathrm{x}$ Prunus amygdalus]. The experiment was performed at a field site $\left(44^{\circ} 13^{\prime} 59.99^{\prime \prime} \mathrm{N}\right.$ and $11^{\circ} 50$ '53.60”E) located in Marzeno (Province of Ravenna, northern Italy), in different plots to avoid any residual effect from the previous year. The orchard was planted in a typical growing area, on a soil classified as a Bathicalcic Cambisols (FAO, 1998), consisting of $19 \%$ total $\mathrm{CaCO}_{3}, 8 \%$ active $\mathrm{CaCO}_{3}, 0.7 \%$ organic matter, $\mathrm{pH} 7.8,27 \%$ clay, $58 \%$ silt and $15 \%$ sand. For replicated treatments and control, each year each plot consisted of a single, non-contiguous, $140 \times 4.5 \mathrm{~m}$ row of trees.

A field study was conducted from 2007 to 2009 on 8-year old nectarine trees (Prunus persica L. Batsch, cv. Big Top grafted onto GF 677 rootstock (Prunus persica $\mathrm{x}$ Prunus amygdalus). The experiment was performed at a field site $\left(44^{\circ} 29^{\prime} 50.16^{\prime \prime} \mathrm{N}\right.$ and $11^{\circ} 57^{\prime} 08.40$ 'E) located in Fusignano (Province of Ravenna, northern Italy), in different plots to avoid any residual effect from the previous year. The orchard was planted in a typical growing area, on a soil classified as a Calcari Gleyic Cambisols (FAO, 1998), consisting of $17 \%$ total $\mathrm{CaCO}_{3}, 12 \%$ active $\mathrm{CaCO}_{3}, 2.3 \%$ organic matter, $\mathrm{pH} 7.8,34 \%$ clay, $62 \%$ silt and $4 \%$ sand. For replicated treatments and control, each year each plot consisted of a single, non-contiguous, $180 \times 4 \mathrm{~m}$ row of trees.

Potato experiments were conducted in 2007 and 2008 at a field site (44 $29^{\prime} 41.08^{\prime \prime} \mathrm{N}$ and $11^{\circ} 57^{\prime 20.73 ” E) ~ l o c a t e d ~ i n ~ F u s i g n a n o ~(P r o v i n c e ~ o f ~}$ Ravenna, northern Italy) in two different plots to avoid any residual effect from the previous year. For replicated treatments and control, each year each plot consisted of a $200 \times 9 \mathrm{~m}$, non-contiguous, field area, including 10 rows of potato plants $(90 \mathrm{~cm}$ between rows, $21 \mathrm{~cm}$ between plants in the row). The tubers were planted on April 17 and April 23 in 2007 and 2008, respectively. Plum, nectarine and potato experimental fields, including plots, were subject to standard cultivation techniques, under the Regional regulations for integrated pest management (Regione Emilia Romagna). Tomato experiments were conducted in the open field and in the greenhouse. The open field study was conducted in 2007 and 2008 at a field site $\left(42^{\circ} 53^{\prime} 09.47^{\prime \prime} \mathrm{N}\right.$ and $13^{\circ} 47$ '52.83”E) located in Monsampolo del Tronto (Province of Ascoli Piceno, central Italy) in two different plots to avoid any residual effect from the previous year. For replicated treatments and control, each year plot size was $7 \mathrm{~m}^{2}$, consisting of 20 tomato plants. The soil is classified as a Calcari-Fluvic Cambisols (FA0, 1998) consisting of $19.4 \%$ total $\mathrm{CaCO}_{3}, 7.2 \%$ active $\mathrm{CaCO}_{3}, 2.2 \%$ organic matter, $\mathrm{pH} 7.6,28.3 \%$ clay, $20 \%$ silt and 52\% sand. Seeds were sown on March 27 and March 25, and were transplanted on May 4 and May 2 in 2007 and 2008, respectively. The tomato field trial was managed with standard cultivation techniques, under the Regional regulations for integrated pest management (Regione Marche).The greenhouse experiments were conducted in 2008 and 2009 in Montanaso Lombardo (Province of Lodi) Italy $\left(45^{\circ} 2031.01 \mathrm{~N} 9^{\circ} 2653.97 \mathrm{E}\right)$ and the cultivation was carried out in hydroponic culture. Tomato plants were grown in an open rockwool sys- 
tem as spring crop. We used Rockwool Grodan Master slabs (100x20x7.5 cm) filled with the organic medium. In 2008, tomato seeds were sown individually in special rockwool minicubes on March 3 , and after two weeks minicubes containing tomato seedlings were inserted into rockwool starter cubes $(10 \times 10 \mathrm{~cm})$. Tomato transplants were placed onto rockwool production slabs on April 29. Tomato plants were grown until the $7^{\text {th }}$ cluster. In 2009, all the cultural practices were repeated as in 2008, except for the dates on which sowing and transplantation on rockwool slabs took place (March 25 and May 15, respectively). For replicated treatments and control, each year each plot consisted of 8 plants.

In the open field experiments two treatment systems were used, and two pre-market preparations of fertilizer containing potassium iodide (KI) and coformulants (BMS Micro-Nutrients NV, Bornem, Belgium) were applied. The treatments were as follows: i) foliar spray application of a liquid fertilizer with $25 \mathrm{~g} \mathrm{~L}^{-1} \mathrm{I}$; and ii) soil application of a crystalline fertilizer with $90 \mathrm{~g} \mathrm{Kg}^{-1}$ I. The dose of iodine called $\mathrm{N}$ $\left(125 \mathrm{~g} \mathrm{ha}^{-1}\right)$ was used as reference. The iodine dose was adjusted each year in order to increase iodine concentration in the plants. Details of all treatments and doses in each year of trials (2007, 2008 and 2009) are summarized in Table 1. For nectarine trees, both soil and foliar spray treatments were applied. For plum tree, only foliar spray treatments were applied. For potato and open field tomato, soil, foliar spray, and soil plus foliar spray treatments were applied. In all field trials, a control plant without any iodine application was included every year. Irrigation and treatments were applied by an automated trickle irrigation system, and each plum tree, nectarine and potato treatment was replicated twice according to a completely randomized design, except for plum tree in 2007, when they were performed without replicates. Tomato field treatments were replicated three times, according to a randomized block design, except for 2007 , when they were performed without replicates.

In hydroponic culture, only the $25 \mathrm{~g} \mathrm{~L}^{-1} \mathrm{I}$ liquid fertilizer (BMS Micro-Nutrients NV) was used for experiments; three treatments, $1 \mathrm{mM}, 2 \mathrm{mM}$ and $5 \mathrm{mM}$ of potassium iodide (KI), were applied to tomato plants. The control treatment consisted of applying the complete growth solution without any iodine. Each hydroponic treatment was replicated three times according to a randomized block design.

Iodine treatments on nectarine trees were split into four applications between May and June, and fruit samples were harvested at the beginning of July of each year (2007-2009). Iodine treatments on plum trees were split into four applications between July and August, and fruit samples were harvested at the end of August of each year (20072009). At the end of August 2008, leaves and branches of plum tree were also harvested. Iodine doses on potato plants were split into four applications between May and June, and tuber samples were harvested at the end of August of each year (2007-2008). At the end of July 2008, leaves and stems were also harvested. In 2007 and 2008, iodine treatments on tomato plants grown in open field were split into four applications between June and July, and fruit samples were harvested in July of each year. Finally, iodine treatments on tomato plants grown in hydroponic culture were applied between June and July both in 2008 and 2009, and split into four and five applications, respectively. Fruit samples were then harvested at the end of July of each year. Dry mass (oven-dried at $180^{\circ} \mathrm{C}$ for one day) was determined for leaves, stems and tubers of potato and for leaves, branches and fruits of plum tree.

\section{Processing and storage treatments}

Effect of postharvest storage and processing (cooking) for potato tubers, and storage and processing (peeling) for nectarine fruits were analyzed in 2008. Nectarine fruit peeling was performed by simply eliminating 2-3 mm thick peel with a clean knife. For potato tuber, two cooking methods were used, and processing times and temperatures were based on the optimum times and required temperatures to cook the average sample.

\section{Boiling}

Water was brought to the boil on a gas stove. Potato samples treated with doses of iodide $(\mathrm{N})$ of $2 \mathrm{~N}$, and $40 \mathrm{~N}$ were cooked for $25 \mathrm{~min}$ in the boiling water. After cooking, the leachate was removed and discarded. The cooked potato sample was frozen at $-20^{\circ} \mathrm{C}$ until iodine determination.

\section{Bake}

A gas oven was heated to $200^{\circ} \mathrm{C}$. Potato samples treated with a dose of $40 \mathrm{~N}$ were cooked for $45 \mathrm{~min}$. Cooked samples were frozen at $-20^{\circ} \mathrm{C}$ until iodine determination.

In order to analyze the effect of postharvest storage, samples of potato tubers, treated with doses $2 \mathrm{~N}$, and $40 \mathrm{~N}$, and of nectarine fruits, treated with dose $\mathrm{N}$ (Table 1), harvested in the periods indicated above, were placed in a cold storage room for six months at $10^{\circ} \mathrm{C}$, and for two weeks at $5^{\circ} \mathrm{C}$, respectively.

Table 1. Details of doses and field treatments applied in four horticultural and fruit tree species from 2007 to 2009 , both to the soil and as foliar spray. Also in greenhouse hydroponic culture for tomato. The dose of iodine $\mathrm{N}\left(125 \mathrm{~g} \mathrm{ha}^{-1}\right)$ was used as reference in the field trials. Iodine doses used in hydroponic culture are expressed as $\mathrm{mM}$ of $\mathrm{KI}$.

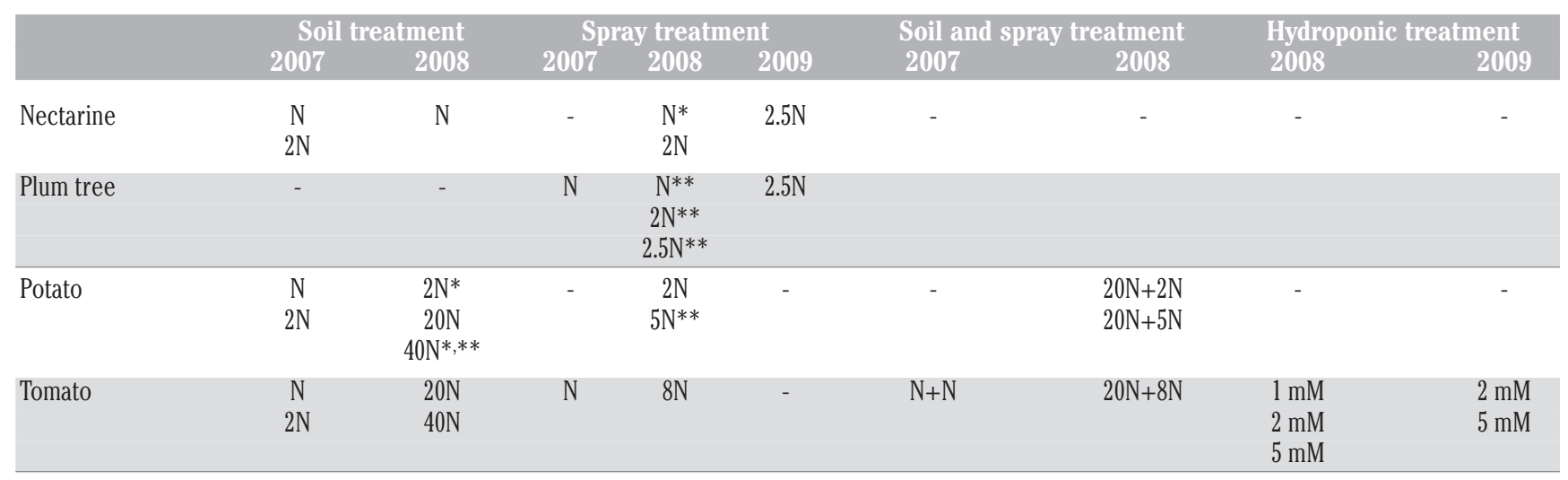

*Treatments from which samples for post-harvest, peeling and cooking experiments were collected; **treatments from which also samples of vegetative parts were collected. 


\section{lodine content analysis}

Iodine content in plum and tomato fruit was determined with peel and in potato tubers without peel. In nectarine fruit, due to consumption habits, iodine content was determined both with and without peel. Iodine content in plant tissues was determined using the USEPA Method $3052\left(\mathrm{HNO}_{3}-\mathrm{H}_{2} \mathrm{O}_{2}\right.$, microwave digestion), and an inductively coupled plasma mass spectrometry (ICP-MS) analysis procedure. Chemical analyses were performed at NEOTRON S.p.a. (Santa Maria di Mugnano, Modena, Italy). The closed digestion was performed by placing the sample in a polytetrafluoroethylene (PTFE) vial (or bomb). After adding the digestion reagents $\left(10 \mathrm{~mL} \mathrm{HNO}_{3} 65 \%\right.$ and $2 \mathrm{~mL} \mathrm{H}_{2} \mathrm{O}_{2}$ $30 \%$ ), the bomb was hermetically sealed and located in a microwave oven for irradiation. The determination of iodine by ICP-MS was performed by using isotope dilutions of $\mathrm{I}^{127}$, and iodine concentrations in the samples were determined by means of a calibration curve obtained with the method of standard additions (Larsen and Ludwigsen, 1997).

\section{Statistical analysis}

Results obtained were expressed as means \pm SEM and statistical analysis was performed according to the Systat 12 statistical package (Systat Software, Inc.). Data were analyzed using a general linear model (GLM). Duncan's multiple range test (DMRT) was used to examine differences between groups and among group means. $\mathrm{P} \leq 0.05$ was considered statistically significant.

\section{Results}

\section{lodine accumulation in crops}

Tables 2, 3, 4 and 5 show the relation between iodine content in the edible portion of different crops, and the dose of exogenous iodine in soil, spray and hydroponic applications.

Table 2 shows iodine accumulation in nectarine and plum fruit over the three years of the experiment. The iodine content in nectarine fruit increased significantly after foliar spray application at dose $\mathrm{N}$ only in 2007 , while in 2008 , the increase was significant only at the highest dose of applied iodide $(2.5 \mathrm{~N})$. In the first year of the experiment (2007), iodine content in nectarine fruit treated with dose $\mathrm{N}$ applied as foliar spray was determined with and without peel (Figure 1A) and no significant change in iodine content was observed. Thus, in the following two years, iodine content in fruit was determined only with peel. The iodine content in plum fruit was determined only with peel. A significant increase in iodine content in plum fruit was observed already at the lowest dose of iodide (N) applied as a foliar spray (2008). Considering all the treatments applied (2007-2009), nectarine and plum tree accumulated only low amounts of iodine in their edible tissues: from 4.0 to $14.3 \mu \mathrm{g} 100 \mathrm{~g}^{-1}$ and from 5.6 to $9.5 \mu \mathrm{g} 100 \mathrm{~g}^{-1}$, respectively (Table 2).

Table 3 shows iodine accumulation in potato tubers over the two

Table 2. Iodine accumulation in nectarine and plum fruits during three years of experiment. ${ }^{\circ}$

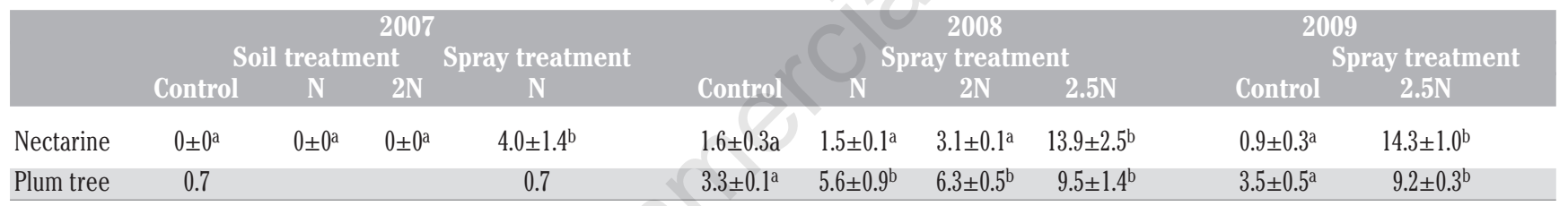

${ }^{\circ}$ Iodine content $\left(\mu \mathrm{g} 100 \mathrm{~g}^{-1}\right.$, FW) is expressed as replicate means \pm SEM. a,bValues followed by different letters are significantly different by Duncan's multiple range test $(\mathrm{P} \leq 0.05)$.

Table 3. Iodine accumulation in potato tubers during two years of experiment. ${ }^{\circ}$

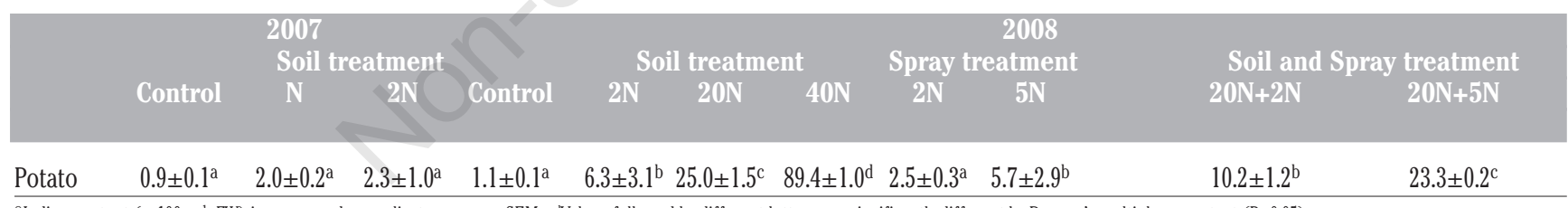

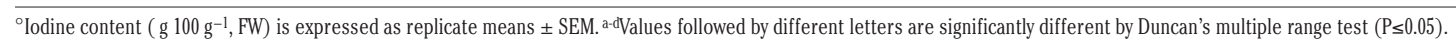

Table 4. Iodine accumulation in fruits of tomato grown in open field during two years of experiment. ${ }^{\circ}$

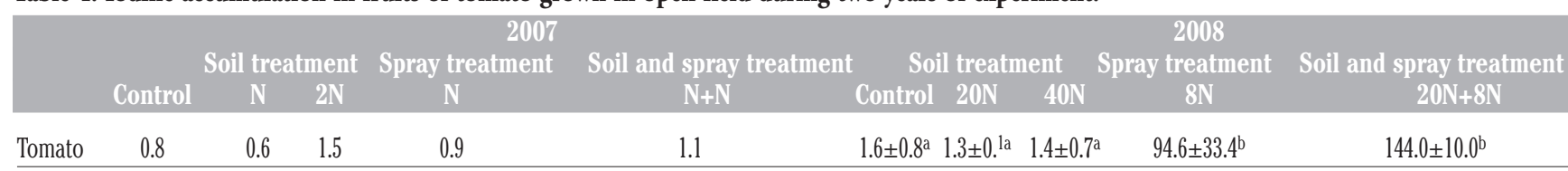

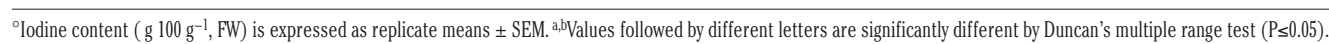

Table 5. Iodine accumulation in fruits of tomato grown in hydroponic culture during two years of experiments. ${ }^{\circ}$

\begin{tabular}{|c|c|c|c|c|c|c|c|}
\hline & & Hydroponic & lent & & & $\begin{array}{c}2009 \\
\text { roponic treatı }\end{array}$ & \\
\hline & Control & $1 \mathrm{mM}$ & $2 \mathrm{mM}$ & $5 \mathrm{mM}$ & Control & $2 \mathrm{mM}$ & $5 \mathrm{mM}$ \\
\hline Tomato & $4.6 \pm 1.6 \mathrm{a}$ & $454.5 \pm 151.5^{b}$ & $613.0 \pm 54.0^{\mathrm{b}}$ & $765.0 \pm 206.0^{\mathrm{b}}$ & $9.7 \pm 1.1^{\mathrm{a}}$ & $2256.7 \pm 336.2^{\mathrm{b}}$ & $2423.3 \pm 317.6^{\mathrm{b}}$ \\
\hline
\end{tabular}

${ }^{\circ}$ Iodine content ( $\left.\mathrm{g} 100 \mathrm{~g}^{-1}, \mathrm{FW}\right)$ is expressed as replicate means \pm SEM. a,bValues followed by different letters are significantly different by Duncan's multiple range test ( $\left.\mathrm{P} \leq 0.05\right)$. 
years of the experiments. The iodine content in tubers was determined only without peel. During the first year of treatment, no significant uptake was observed after soil treatments at the lowest dose $\mathrm{N}$ and $2 \mathrm{~N}$ doses; therefore, during the second year, the iodine doses were increased to 20 and $40 \mathrm{~N}$. Furthermore, foliar spray treatments were also applied, alone and in combination with soil treatment at $20 \mathrm{~N}$. The iodine content in potato tubers increased as a greater amount of iodine was applied. The iodine uptake was higher after soil treatments than after foliar spray treatments, and no significant increase was observed when soil applications were combined with foliar applications. There was a significant increase in iodine content compared to the control plants after soil treatments at 20 and $40 \mathrm{~N}$ and after foliar spray treatment at $5 \mathrm{~N}$; the amounts of iodine accumulated in the tubers were 25.0, 89.4 and $5.7 \mu \mathrm{g} 100 \mathrm{~g}^{-1}$, respectively (Table 3 ).

Table 4 shows iodine accumulation in tomato fruit grown in the open field over the two years of experiments. During the first year of treatment, no significant difference in uptake was observed either after soil treatments at $\mathrm{N}$ and $2 \mathrm{~N}$, spray treatment at $\mathrm{N}$ or after a combination of soil and spray treatments; therefore, during the second year, the iodine doses were increased. Significant uptake was observed after foliar spray application at $8 \mathrm{~N}\left(94.6 \mu \mathrm{g} 100 \mathrm{~g}^{-1}\right)$; however, no significant uptake was obtained after soil treatments and no significant increase in iodine uptake was observed when foliar applications were combined with soil applications (Table 4). During 2007, the iodine uptake obtained in fresh market tomato grown in the open field was unsatisfactory; therefore, since 2008, a hydroponic system has been included.

Table 5 shows the iodine accumulation in fruit of tomato grown in hydroponic culture over the two years of experiments. In 2008 , a significant iodine uptake was observed at a lower dose of iodide ( $1 \mathrm{mM}$ ) and no significant increase was observed with a further increase in the dose. Significant iodine uptake was observed with the lower dose of iodide ( $2 \mathrm{mM})$ in 2009 and this was higher than in 2008. Furthermore, no significant increase was observed with a further increase in the dose. Tomatoes grown in hydroponic culture successfully accumulated

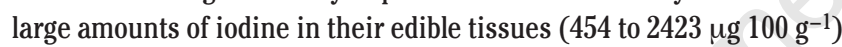
although this varied widely among replicates.

\section{Effect of postharvest storage and processing on iodine uptake}

No significant change in iodine content was observed either in nectarine fruit after storage and peeling, or in potato tubers after storage (Figure 1). The effect of cooking on iodine content was investigated in potato tubers (Figure 1B). A significant increase in iodine content was observed after baking whereas a significant decrease in iodine content was observed after boiling.

\section{lodine distribution in different plant organs}

Figure 2 shows iodine distribution in different organs of plum tree (Figure 2A) and potato (Figure 2B) as a function of iodine doses applied. Iodine content is expressed as dry weight (DW). Iodine was mainly accumulated in the leaves and only a small portion of iodine uptake was transported to the plum tree branches and fruit, and to potato stems and tubers. The ratio of I in leaves to I in fruit in plum tree was 35:1, 71:1 and 59:1 for foliar sprays treatments at N, $2 \mathrm{~N}$ and $2.5 \mathrm{~N}$, respectively, and the ratio of $\mathrm{I}$ in leaves to $\mathrm{I}$ in branches was 4:1, 9:1 and 11:1 for foliar sprays treatments at $\mathrm{N}, 2 \mathrm{~N}$ and $2.5 \mathrm{~N}$, respectively (Figure 2A). The ratio of I in leaves to I in tubers in potato was 343:1 for foliar spray treatment at $5 \mathrm{~N}$ whereas for soil treatment at $40 \mathrm{~N}$, the ratio was 9:1, and the ratio of $\mathrm{I}$ in leaves to $\mathrm{I}$ in stems was 9:1 for foliar spray treatment at $5 \mathrm{~N}$ and for soil treatment at $40 \mathrm{~N}$ the ratio was 3:1 (Figure 2B).

Iodine content in leaves of plum tree increased with increasing amounts of iodine whereas a significant increase was already observed in branches and in fruit of plum at the lowest dose (N). Increasing the dose of application did not lead to any significant further increase in iodine content (Figure 2A). Iodine content in potato leaves was higher after foliar spray treatment than after soil treatment. A significant increase in iodine content was observed in potato stems under both
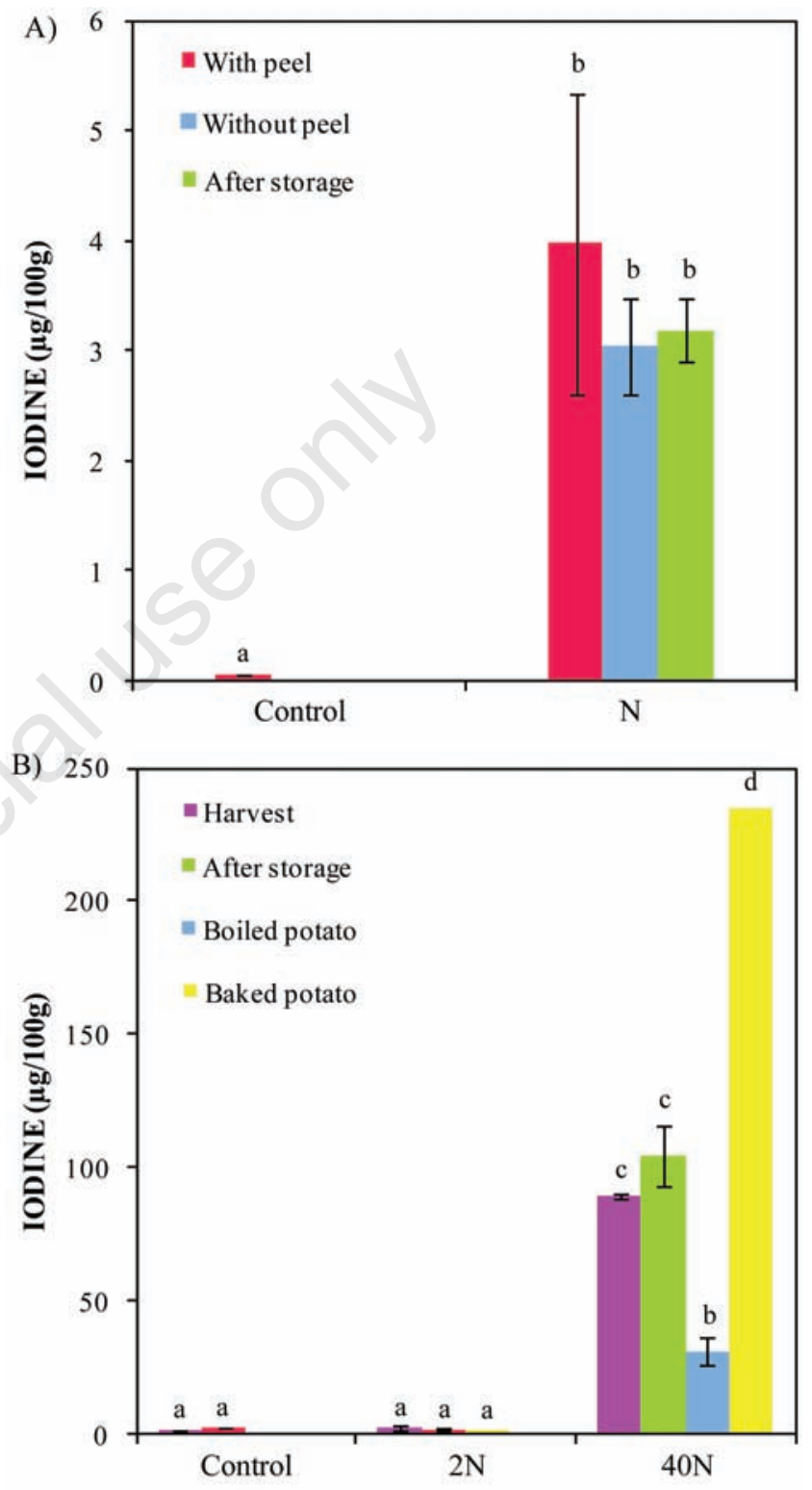

Figure 1. A) Effects of postharvest storage and peeling on iodine content in nectarine fruit treated with foliar spray dose $\mathrm{N}$. Iodine content $\left(0 \mu \mathrm{g} 100 \mathrm{~g}^{-1}\right)$ in untreated nectarine (control) analyzed only in fruit with peel is reported on the $x$ axis to indicate the significant difference $(\mathbf{a}<\mathbf{b})$ by Duncan's multiple range test $(\mathrm{P} \leq 0.05)$. B) Effects of postharvest storage and processing (cooking) on iodine content in potato tubers. Iodine content in untreated potato tubers (control) was analyzed at harvest and after storage, while iodine content in potato treated with $2 \mathrm{~N}$ dose was analyzed at harvest, after storage and after boiling. Different letters indicate significant difference $(\mathbf{a}<\mathbf{b}<\mathbf{c}<\mathbf{d})$ by Duncan's multiple range test $(\mathbf{P} \leq \mathbf{0 . 0 5})$ both within and between groups. Data refer to year 2007 for nectarine fruit and to 2008 for potato tubers; iodine content ( $\mu \mathrm{g} 100 \mathrm{~g}^{-1}, \mathrm{FW}$ ) is expressed as replicate means; bars indicate standard errors. 
treatments compared to the control, but no significant change in iodine content was observed after foliar spray treatment at $5 \mathrm{~N}$ compared with soil treatment at $40 \mathrm{~N}$. Iodine content in potato tubers was higher after soil treatment than after foliar spray treatment (Figure 2B).

\section{Discussion}

In this study, the uptake of iodine in soil, spray and hydroponic applications, and its accumulation in the edible portion of plants were studied in two fruit tree and two horticultural species. Clear differences in iodine accumulation were observed among the four crops, between applications (soil and foliar spray) and between production systems
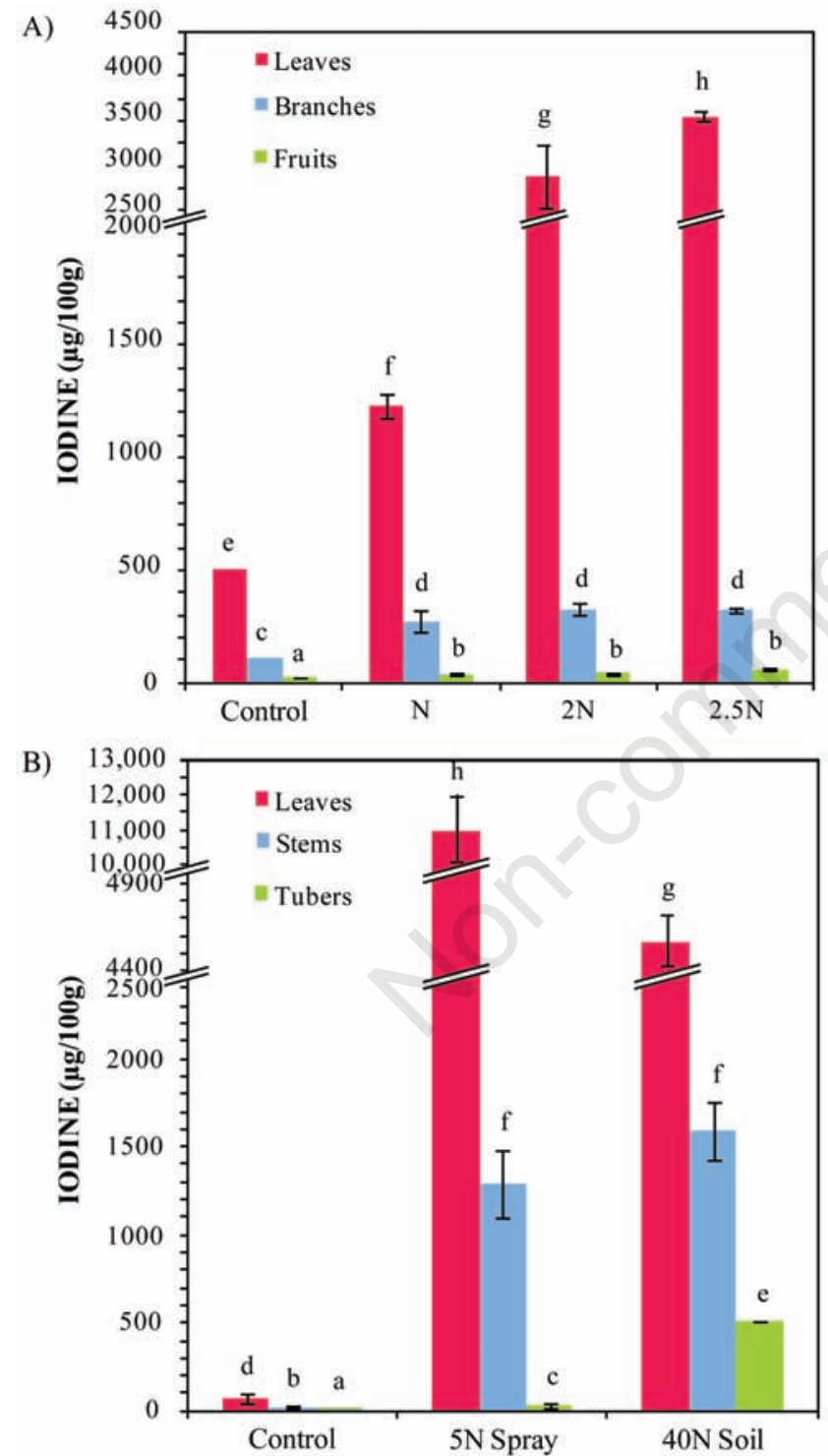

Figure 2. Iodine distribution in different organs of (A) plum tree and (B) potato as a function of iodine doses applied. Data refer to year 2008. Iodine content ( $\mu \mathrm{g} 100 \mathrm{~g}^{-1}$, DW) is expressed as replicate means; bars indicate standard errors; different letters indicate significant difference $(\mathbf{a}<\mathbf{b}<\mathbf{c}<\mathbf{d}<\mathrm{e}<\mathrm{f}<\mathrm{g}<\mathrm{h})$ by Duncan's multiple range test $(P \leq 0.05)$ both within and between groups. (open field and greenhouse hydroponics). As regards differences among the four crops observed in the open field system, the maximum iodine content ranged from 9.5 and $14.3 \mu \mathrm{g} 100 \mathrm{~g}^{-1}$ for plum and nectarine fruit, and to 89.4 and $144.0 \mu \mathrm{g} 100 \mathrm{~g}^{-1}$ for potato tuber and tomato fruit, respectively (Tables 2, 3 and 4). Iodine doses could not be increased in both fruit tree species to increase the iodine accumulation in edible tissues because of phytotoxic symptoms shown by foliarsprayed plants at increased doses. The iodine content in tomato fruit and potato tubers was much higher than in nectarine and plum fruit. This suggests that these horticultural crops (potato and fresh market tomato) might be a better target for strategies to improve dietary iodine supply. As far as differences between soil and foliar applications are concerned, the iodine content in nectarine, plum and tomato fruit increased significantly only after foliar spray treatments, even though fruit trees, nectarine and plum, accumulated much lower amounts of iodine in their edible tissues than tomato (Tables 2 and 4) while the iodine uptake in potato tubers was higher after soil treatments than after foliar spray treatments (Table 3). In order to further clarify the mechanisms of iodine uptake, we investigated the distribution of iodine in potato stem and leaves, and in plum tree fruit, leaves and branches. The transpiring plant parts, i.e. the leaves, contained much more iodine than the fruit and tubers, in agreement with data reported by other authors (Weng et al., 2003; Zhu et al., 2003; Dai et al., 2004; Hong et al., 2008; Voogt et al., 2010). Indeed, the flow of mineral nutrients and water from roots to shoots through the xylem is reduced in organs with low rates of transpiration such as fruit and tubers (Herrett et al., 1962).

It has been suggested that plant root cells take up iodine as the iodide anion (Umaly and Poel, 1971; Mackowiak and Grossl, 1999; Zhu et al., 2003; Blasco et al., 2008; Caffagni et al., 2011), and that $\mathrm{I}^{-}$follows the chloride $\left(\mathrm{Cl}^{-}\right)$transport pathway with $\mathrm{H}+$ /anion symporters catalysing $\mathrm{I}^{-}$uptake and anion channels releasing $\mathrm{I}^{-}$into the xylem (White and Broadley, 2001; Roberts, 2006). Other authors demonstrated that iodine was easily accumulated in roots and leaves (Mackowiak and Grossl, 1999; Zhu et al., 2003; Dai et al., 2004, 2006; Kashparov et al., 2005; Mackowiak et al., 2005; Blasco et al., 2008), and little iodine was considered to have been reallocated via the phloem to fruit or seeds (Herrett et al., 1962; Muramatsu et al., 1993, 1995). However, Landini et al. (2011) showed that iodine was also stored in tomato fruit after leaf treatment. This suggests that a moderate phloem flux of iodine occurred, in agreement with our data collected in the open field where a significant increase of iodine in tomato fruit was obtained only after foliar spray treatments. In the case of potatoes, it was suggested that xylem connections between tubers and basal roots are non-functional (Kratzke and Palta, 1985), so iodine might be directly absorbed from soil through the epidermis. This might explain the higher iodine uptake in potatoes treated with soil application.

The hydroponic system provides excellent opportunities for biofortification with iodine (Blasco et al., 2008; Voogt et al., 2010). This is the most efficient system to control plant uptake of nutrients as the iodine concentration in the root environment can be managed quite simply. Fresh market tomato is one of the crops grown commercially in hydroponic systems and was shown to be a very suitable crop for iodine uptake (Caffagni et al., 2011). In the present study, tomatoes grown in hydroponic culture successfully accumulated up to $2423 \mu \mathrm{g} 100 \mathrm{~g}^{-1}$ of iodine in their edible tissues, much more than tomato grown in an open field system. Considering a single serving of this vegetable as 100 $\mathrm{g}$ of tomato salad, the iodine content obtained in hydroponic culture was approximately 3 -fold the RDA (determined for adults as $150 \mu \mathrm{g}$ day $^{1}$ ) for plants treated with the lowest dose of application $(1 \mathrm{mM})$ and 16 -fold RDA for plants treated with $5 \mathrm{mM}$. The results of the open field experiments showed successful iodine accumulation in tomato fruit treated with foliar spray application at $8 \mathrm{~N}$. Considering a single serving of this vegetable as $100 \mathrm{~g}$ of tomato salad, the iodine contents were 
enough to reach approximately $63 \%$ RDA $\left(94.6 \mu \mathrm{g} 100 \mathrm{~g}^{-1}\right)$.

A second aim of this work was to investigate the iodine content of nectarine fruit after both postharvest storage and peeling, and the iodine content of potato tubers after both postharvest storage and cooking. No significant change in iodine content was observed between peeled and unpeeled fruit, suggesting that iodine might be stored within the flesh of fruit and therefore consumption habits do not influence the iodine intake. Food preservation methods, such as deep freezing and freeze drying, were reported to reduce the iodine content of food by as much as $20-25 \%$ (Lee et al., 1994). However, our data show no significant change in iodine content after postharvest non-freezing storage either in nectarine fruit or in potato tubers (Figure 1). These findings showed that non-freezing storage could be the most appropriate method for preserving these crops once enriched. It has been shown that cooking with water or steam causes a greater loss of iodine in comparison to, for example, roasting or frying (Goindi et al., 1995). In fact, frying and grilling were reported to reduce the iodine content of food by $25 \%$, while boiling may result in a loss of up to $60 \%$ (Lee et al., 1994). This was confirmed by our data that showed that iodine content was reduced by $65 \%$ after boiling (Figure 1B). Finally, it has been suggested that cooking methods with high-temperature oil and baking at high temperature (e.g. $360^{\circ} \mathrm{C}$ for Nan bread) may result in the volatilization of iodine (Zhang et al., 2000; Zhu et al., 2003). However, in the present study, iodine content in tubers was increased significantly by $165 \%$ after baking, probably due to water losses that caused an increase in iodine concentration. On the other hand, baking at $200^{\circ} \mathrm{C}$ did not result in iodine volatilization (Figure 1B). Baking might, therefore, be the best way to cook potatoes to increase iodine intake and to prevent IDD, since a single serving $(100 \mathrm{~g})$ of baked potato treated with soil application at $40 \mathrm{~N}$ was enough to reach full RDA.

\section{Conclusions}

Horticultural and fruit tree species can absorb and accumulate iodine when exogenous iodine is applied. However, an obvious discrepancy is observed in its absorption among crops. Based on the results of these experiments, it can be concluded that priority should be given to horticultural crops as candidates for iodine biofortification and that salad of fresh market tomato treated with foliar spray application at $8 \mathrm{~N}$ and baked potatoes after soil application at $40 \mathrm{~N}$ could be considered potential functional foods for IDD prevention. Our results suggest that iodine might be stored within the flesh of fruit and that non-freezing might be the most appropriate storage method for the crops studied in order to retain the iodine content. Furthermore, our results confirmed that hydroponic culture is the most efficient system for nutrient uptake. However, sufficiently good results of iodine accumulation in two horticultural crops were also obtained in normal Italian cultivation practice.

\section{References}

Andersson M, de Benoist B, Darnton-Hill I, Delange, F., 2007. Iodine Deficiency in Europe. A Continuing Public Health Problem. WHO Press, Geneva, Switzerland.

Blasco B, Rios JJ, Cervilla LM, Sanchez-Rodrigez E, Ruiz JM, Romero L, 2008. Iodine biofortification and antioxidant capacity of lettuce: potential benefits for cultivation and human health. Ann. Appl. Biol. 152:289-299.

Caffagni A, Arru L, Meriggi P, Milc J, Perata P, Pecchioni N, 2011. Iodine fortification plant screening process and accumulation in tomato fruits and potato tubers. Commun. Soil Sci. Plant Anal. 42:706-718.

Dai JL, Zhu YG, Huang YZ, Zhang M, Song JL, 2006. Availability of iodide and iodate to spinach (Spinacia oleracea L.) in relation to total iodine in soil solution. Plant Soil 289:301-308.

Dai JL, Zhu YG, Zhang M, Huang YZ, 2004. Selecting iodine-enriched vegetables and the residual effect of iodate application to soil. Biol. Trace Elem. Res. 101:265-276.

Delange F, de Benoist B, Alnwick D, 1999. Risks of iodine-induced hyperthyroidism following correction of iodine deficiency by iodized salt. Thyroid 9:545-556.

FAO, 1998. World Reference Base for Soil Resources. FA0 Publ., Roma, Italy.

FAO/WHO, 2004. Iodine. pp 303-317 in: Human vitamin and mineral requirements. Report of a Joint FAO/WHO Expert Consultation, 2nd ed. WHO Press, Geneva, Switzerland.

Goindi G, Karmarkar MG, Kapil U, Jagannathan J, 1995. Estimation of losses of iodine during different cooking procedures. Asia Pac. J. Clin. Nutr. 4:225-227.

Henry CJ, 2010. Functional foods. Eur. J. Clin. Nutr. 64:657-659.

Herrett RA, Hatfield HH, Crosby DG, Vlitos AJ, 1962. Leaf abscission induced by iodine ion. Plant Physiol. 37:358-363.

Hetzel BS, 1983. Iodine deficiency disorders (IDD) and their eradication. Lancet 2:1126-1129.

Hong CL, Weng HX, Qin YC, Yan AL, Xie LL, 2008. Transfer of iodine from soil to vegetables by applying exogenous iodine. Agron. Sustain. Dev. 28:575-583.

Jopke P, Bahadir M, Fleckenstein F, Schnug E, 1996. Iodine determination in plant materials. Commun. Soil Sci. Plant Anal. 27:741-751.

Kashparov V, Colle C, Zvarich S, Yoschenko V, Levchuk S, Lundin S, 2005. Soil-to-plant halogens transfer studies: 1. Root uptake of radioiodine by plants. J. Environ. Radioact. 79:187-204.

Kratzke MG, Palta JP, 1985. Evidence for the existence of functional roots on potato tubers and stolons: significance of water transport to the tuber. Am. Potato J. 62:227-236.

Landini M, Gonzali S, Perata P, 2011. Iodine biofortification in tomato. J. Plant Nutr. Soil Sci. 174:480-486.

Larsen EH, Ludwigsen MB, 1997. Determination of Iodine in food-related certified reference materials using wet ashing and detection by Inductively Coupled Plasma Mass Spectrometry. J. Anal. Atom. Spectrom. 12:435-439.

Lee SM, Lewis J, Buss D, 1994. Iodine in British food and diets. Brit. J. Nutr. 72:435-446.

Mackowiak CL, Grossl PR, 1999. Iodate and iodide effects on iodine uptake and partitioning in rice (Oryza sativa L.) grown in solution culture. Plant Soil 212:135-143.

Mackowiak CL, Grossl PR, Cook KL, 2005. Iodine toxicity in a plant solution system with and without humic acid. Plant Soil 269:141-150.

Moleti M, Lo Presti VP, Campolo MC, Mattina F, Galletti M, Mandolfino M, Violi MA, Giorgianni G, De Domenico D, Trimarchi F, Vermiglio F, 2008. Iodine prophylaxis using iodized salt and risk of maternal thyroid failure in conditions of mild iodine deficiency. J. Clin. Endocrinol. Metab. 93:2616-2621.

Muramatsu Y, Uchida S, Ohmomo Y, 1993. Root uptake of radioiodine by rice plants. J. Radiat. Res. 34:214-220.

Muramatsu Y, Yoshida S, Bannai T, 1995. Tracer experiments on the behaviour of radioiodine in the soil-plant-atmosphere system. J. Radioanal. Nucl. Chem. 194:303-310.

Regione Emilia Romagna. Disciplinari di Produzione Integrata. Available from: http://www.ermesagricoltura.it

Regione Marche. Disciplinare per la Produzione Integrata delle Colture. Available from: http:/www.agri.marche.it

Roberts SK, 2006. Plasma membrane anion channels in higher plants and their putative functions in roots. New Phytol. 169:647-666.

Stanbury JB, Ermans AE, Bourdoux P, Todd C, Oken E, Tonglet R, Vidor 
G, Braverman LE, Medeiros-Neto G, 1998. Iodine-induced hyperthyroidism: occurrence and epidemiology. Thyroid 8:83-100.

Umaly RC, Poel LW, 1971. Effects of iodine in various formulations on the growth of barley and pea plants in nutrient solution culture. Ann. Bot. 35:127-131.

UNICEF/WHO, 1994. World summit for children - Mid decade goal: iodine deficiency disorders (IDD). UNICEF-WHO Joint Committee on Health Policy, Geneva, Switzerland.

Voogt W, Holwerda HT, Khodabaks R, 2010. Biofortification of lettuce (Lactuca sativa L.) with iodine: the effect of iodine form and concentration in the nutrient solution on growth, development and iodine uptake of lettuce grown in water culture. J. Sci. Food Agric. 90:906-913.

Welch RM, Graham RD, 1999. A new paradigm for world agriculture: meeting human needs: productive, sustainable, nutritious. Field Crop. Res. 60:1-10.

Weng HX, Weng JK, Yan AL, Hong CL, Yong WB, Qin YC, 2008. Increment of iodine content in vegetable plants by applying iodized fertilizer and the residual characteristics of iodine in soil. Biol. Trace Elem. Res. 123:218-228.
Weng HX, Weng JK, Yong WB, Sun ZW, Zhong H, 2003. Capacity and degree of iodine absorbed and enriched by vegetable from soil. J. Environ. Sci. 15:107-111.

White PJ, Broadley MR, 2001. Chloride in soils and its uptake and movement within the plant: a review. Ann. Bot. 88:967-988.

WHO/UNICEF/ICCIDD, 1996. Recommended iodine levels in salt and guidelines for monitoring their adequacy and effectiveness. WHO Press, Geneva, Switzerland.

WHO/UNICEF/ICCIDD, 2007. Assessment of iodine deficiency disorders and monitoring their elimination. A guide for programme managers, $3^{\text {rd }}$ ed. WHO Press, Geneva, Switzerland.

Winger RJ, Konig J, House DA, 2008. Technological issues associated with iodine fortification of foods. Trends Food Sci. Technol. 19:94101.

Zhang L, Chen Z, Wang J, Bao J, 2000. Iodine loss from iodinised salt during processing, sale and consumption. Zhejiang Prev. Med. 12:32-34.

Zhu YG, Huang YZ, Hu Y, Liu YX, 2003. Iodine uptake by spinach (Spinacia oleracea L.) plants grown in solution culture: effects of iodine species and solution concentrations. Environ. Int. 29:33-37. 